\title{
Community Mental Health Centers as Human Service Organizations
}

\section{YEHESKEL HASENFELD}

University of Michigan

What is attempted in this article is to present an organizational perspective on community mental health centers (CMHCs) that could provide a clearer understanding of the structures and processes observed in them. The perspective is derived from a broader application of organizational theory to human service organizations. It is based on the assumption that human service organizations are a distinct set of bureaucracies whose "principal function is to protect, maintain, or enhance the personal well-being of people by defining, shaping, or altering their personal attributes" (Hasenfeld, 1983: 1). I argue that in trying to understand these organizations, dominant organizational theories that have been formulated with industrial organizations as their empirical referents are not readily applicable. In particular, I propose that to understand these organizations one must call upon organizational theories that depart in significant ways from the rational models of organizations. As will be apparent from the ensuing discussion, I rely more heavily on a political economy perspective (Wamsley and Zald, 1976) and on the institutional model of organizational structure (Meyer and Rowan, 1977; Meyer et al., 1981).

Applying this organizational perspective to CMHCs in order to arrive at some overall understanding of their key structural features is exceedingly difficult because of the immense variations among them. I have tried to identify modal structural characteristics while fully recognizing that in doing so I may have overlooked the considerable variance they display.

As a class of organizations, CMHCs (and I refer here specifically to publicly funded CMHCs) epitomize the distinctiveness of human service organizations. First, their "raw materials" are people whom they attempt to process, sustain, and change. A key characteristic of the attributes of the people served by CMHCs is that many are volatile, 
unstable, and unpredictable. More important, the raw material is vested with values and, therefore, the organizational technologies of CMHCs are embedded in moral systems. Consequently, the services and technologies of CMHCs are value laden. Second, they function in a task environment that is characterized by turbulence, conflicting interest groups, and fragmented and uncertain resources. Third, the goals of these organizations are inherently ambiguous, contradictory, and unstable. Fourth, they tend to operate indeterminate technologies that lack systematic or complete knowledge on how to attain desired outcomes. Fifth, they have an internal structure that is loosely coupled and in which different professional groups vie for power and dominance.

As will be shown, these structural characteristics of CMHCs represent centrifugal forces generating a conglomerate form of organization. Put differently, CMHCs can be best described as sets of relatively autonomous organizational units held together by headquarters that are responsible for strategic planning and for fiscal and performance control. Symbolic cohesion is provided through a mental health ideology that serves to mobilize institutional legitimation yet permits various interest groups to pursue their own interests in the conglomerate.

It will be also suggested that $\mathrm{CMHCs}$ are relatively new organizational forms in existence for roughly two decades. As a result of organizational newness, CMHCs encounter a great deal of fluctuation and change as they attempt to develop a niche in a turbulent environment.

\section{PEOPLE AS “RAW MATERIAL"}

Probably more than most other human service organizations, CMHCs have an exceptionally broad definition of their clients. Once a community definition of mental illness has been accepted and mandated (Mechanic, 1980), few limits could be established on who is eligible for the services of CMHCs. To quote Dinitz and Beran (1971: 100),

the community mental health system offers an all-inclusive response to the question of who shall be defined as deviant in community mental health terms. Moving well beyond traditional mental health's focus on psychotherapy, the community mental health system displays concern with the definition and management of any behavior that appears to threaten the quality of human existence.

As a result, CMHCs have had to cope with an inflow of clients with extremely diverse attributes and mental health problems who have 
required different service technologies. Furthermore, because CMHCs were also originally mandated to engage in prevention, the community itself and its constituent parts, however amorphously defined, also became one of the raw materials to be worked on. Therefore, CMHCs encounter inputs of clients who are highly heterogeneous, variable, and unstable in both attributes and moral valuation. They range from persons labeled as schizophrenic or mentally retarded to school principals and neighborhood organizations. In addition, as will be emphasized later, the constant shifts in funding sources have forced CMHCs to search for new and different "fundable" mental health needs, thus exacerbating the variability and instability of client inputs.

The inability to delimit, control, and standardize the raw material poses severe production problems to the organization. One response, typically adopted by CMHCs, has been to develop highly differentiated service provision units, each dedicated to a specific cohort of clients. These units are also differentiated by the moral valuation of their clients, thus leading some to be seen as prestigious and others as "dirty work" (Emerson and Pollner, 1975). Other strategies include "creaming," taking only those clients having desirable attributes, or "cooling off," shunting undesirable clients to other organizations or delaying services to them.

The ability of the organization to respond to such a diverse client population necessitates extensive investment of resources in multiple service technologies. As long as the environment is resource rich, as it was for CMHCs during the 1960s and early 1970s, such a strategy is feasible. However, when the environment becomes resource poor-as it has been since the late $1970 \mathrm{~s}$ - economic pressures are built to curb the domain of the organization, to reduce variability of its raw material, and to serve only those clients who enable the organization to procure resources. In recent years, these clients have been, on the one hand, the chronically mentally ill who are supported by public funds and, on the other hand, patients with third-party insurance. An emphasis on serving the chronically mentally ill while reducing the variability of the client input raises new organizational dilemmas. First, because the rate of success in working with such clients is exceedingly low, the ability of CMHCs to maintain high staff morale and to attract talented professionals is diminished. Second, the volatility of these clients in a community setting results in unstable organization-environment relations. Resistance by community groups to after-care programs in their neighborhoods, visibility of unacceptable client behavior in public settings, and difficulties in developing a comprehensive network of supportive community services combine to make CMHCs permeable to frequent, 
yet unpredictable, crises. Third, the low moral valuation of the chronically mentally ill by the general public inevitably tarnishes the general legitimation and public support of the CMHC. To counter these trends enterprising CMHCs have begun to develop corporate subsidiaries that are free to compete in the mental health market for desirable clients.

\section{DEPENDENCE ON A TURBULENT ENVIRONMENT}

Human service organizations are generally more dependent on their task environment and are, therefore, more susceptible to external influences because they normally depend on donors to sustain them. In particular, the establishment of a domain consensus is more problematic because it cannot be negotiated via market mechanisms but rather involves political bargaining with external interest groups controlling key organizational resources.

CMHCs are especially vulnerable to external influences and yet are less able to establish a stable domain consensus because of several interrelated factors. First, they generally face a power disadvantage in their interorganizational exchanges. They are highly dependent on federal, state, and local governments for fiscal resources, yet cannot claim monopoly over the services they provide. They are highly dependent on other organizations - such as general and psychiatric hospitals, departments of social services, and substance abuse programs-to provide critical complementary services to their clients, and yet they cannot readily control the inflow of clients referred to them by these and other organizations.

Second, being mandated to have a very broad domain and to work with community groups, they must, at least symbolically, engage various community interest groups in order to buttress their legitimation. As a result, they are permeable, at the institutional level, to numerous external political and ideological influences. Having embraced a broad mental health ideology rather than a narrow psychiatric orientation (Baker, 1982), they cannot readily buffer themselves from these influences.

Third, as new organizational forms with a formal mandate that overlaps and competes with that of many other human service organizations, the CMHCs have disturbed the political and economic balance in the human services interorganizational network. Coupled with a social action and reform ideology, the CMHCs could not readily occupy a 
stable niche without potentially threatening the domain consensus of other organizations. Analogous to the community decision organizations that emerged through the antipoverty legislations (Warren et al., 1974), CMHCs have had to face, and continue to face, a precarious domain consensus. In a study tracing the early developments of the CMHCs, Connery (1968) documented the numerous organizational difficulties in establishing domain consensus, including conflicts among various governmental units, jurisdictional battles among providers of mental health services, and uncertainties in defining the relevant community boundaries (see also Levine, 1981).

Coupled with the dependency on the task environment, CMHCs are characterized by highly permeable boundaries that make it exceedingly difficult for the organization to buffer itself from external forces and to maintain a distinct identity. There are several sources of such permeability. As noted earlier, CMHCs must transact with client populations that are highly diverse and heterogeneous both in attributes and needs. These clients are frequently routed from other organizations such as hospitals, law enforcement agencies, and welfare departments, with whom the CMHCs must maintain liaison relationships. To serve these clients and keep them in the community, CMHCs must rely on a wide range of services that are controlled by other organizations. Purchase of services, contracts, and other formal and informal exchange relations are indispensable to the survival of the organization. The mental health ideology that CMHCs use to legitimate their activities in itself contributes to the blurring of organizational boundaries through its broad definition of the mental health community. Finally, to the extent that CMHCs undertake community intervention activities such as consultation and prevention they embrace an ever-increasing number of community groups and institutions as relevant elements of their task environments.

Ill-defined and permeable boundaries generate organizational instability since the CMHC cannot effectively buffer its technologies and service delivery systems from these external and frequently shifting influences. As we shall elaborate later, among the chief devices used by CMHCs to cope with permeable boundaries are the decoupling of organizational activities and creation of semi-autonomous organizational units that address specific elements in the task environment.

CMHCs also encounter a turbulent environment in the sense that the external political economy changes frequently. As noted by Price and Smith (1983), CMHCs encountered changes in treatment technologies with the increasing reliance on psychotropic drugs; political changes as reflected in the numerous amendments to the Community Mental 
Health Act; and in economic changes through the introduction of SSI, changes in Medicare and Medicaid regulations, and the shift of federal fundings to block grants. In the relatively short life span of CMHCs they have experienced significant shifts in the populations they are mandated to serve, giving greater emphasis to serving the chronically mentally ill, the mentally retarded, the mentally disabled elderly, and other special populations. The accelerating rate of deinstitutionalization has placed CMHCs in the predicament of having to develop new service modalities and programs that have no precedent. Most important, the CMHCs have also experienced major changes in funding patterns both at the federal and state levels, forcing them to shift from an expanding to a contracting economy. As new organizations, $\mathrm{CMHCs}$ could not rely on stable institutionalized arrangements to secure funds. The life span of funding sources has been quite short, forcing CMHCs to be in a perpetual process of chasing after new funds. Yet, each new source of funding, while providing a new opportunity, also sets additional constraints and contingencies to which the organization must accommodate. These accommodations, both programmatically and structurally, must then be discarded or altered as the chase continues and intensifies.

In sum, as noted by Schulberg and Killilea (1982: 41), CMHCs are

now facing a major, if not fundamental, transition. The federal government's leadership and standard setting role have been radically reduced, resource allocation patterns are being redesigned, and conceptual frameworks more congruent with compact service systems are being trumpeted.

Adapting to a turbulent environment has forced CMHCs to undergo frequent structural changes, and to search for organizational forms that can adapt to such an environment. One key strategy seems to have been the development of relatively autonomous organizational units specializing in a particular segment of the environment, such as a specific client group, funding source, or both. These units may occasionally spin-off from the CMHCs and form subsidiary profit or nonprofit voluntary agencies. A similar strategy has been to provide mandated and other services through contractual arrangements with independent service providers, and to reduce gradually the direct service delivery operations of the CMHC.s. These contracts enable CMHCs to avoid sunken costs, and to be able to respond more quickly to environmental changes.

These and other strategies, however, tend to increase coordination costs, foster fragmentation, and reduce overall service integration. As 
such they may obfuscate some of the original aims envisioned in the founding of CMHCs-namely, service accessibility and comprehensive continuity of care.

\section{MULTIPLE, AMBIGUOUS, AND UNSTABLE GOALS}

It should be quite evident from the above discussion that the ability of CMHCs to establish clear and stable goals is severely curtailed. Of course, it may be argued that few organizations can do so. Moreover, the very utility of the concept of goals in understanding organizational behavior has been questioned by leading organizational theorists (see for example, Hannan and Freeman, 1977; White, 1974). The difficulties emanate from the fact that one cannot ascribe goals to an organization without assuming that it has a "personality." Nor is it possible to link the multiple activities organizations pursue to specific goals. Nonetheless, it is important to recognize that for many human service organizations, particularly those publicly funded, goals are ascribed to them through specific legislative and funding bodies. As such they become organizational facts that influence a broad range of strategic decisions in the organization, particularly regarding the allocation of resources. The political economy of the organization is directly affected by its ability to generate outputs in accordance with these ascribed goals. This is eminently the case with CMHCs. The Community Mental Health Act of 1963 and its subsequent amendments mandated the CMHC to a series of outcome or transitive goals including comprehensiveness, continuity of care, accessibility, responsiveness, community involvement, and prevention. Furthermore, a complex external evaluation system has been deployed by federal and state agencies to monitor CMHCs and to assess their adherence to these ascribed goals. While it is true, as we note later, that such an evaluation is mostly ceremonial (like other forms of accreditation), they do influence the resource allocation rules in the organization.

It is important to note at the outset that these goals are exceedingly abstract, and subject to various and conflicting interpretations. As such, they set the stage for various interest groups to claim recognition under such a broad umbrella. Being inclusive rather than exclusive, such goals attract interest groups as potential beneficiaries. As has been demonstrated repeatedly, the transformation of general legislative mandates to specific organizational goals is a political and economic process involving negotiations, bargaining, and coalition formations among contest- 
ing interest groups (see for example, Bardach, 1977). In the case of the CMHCs these contesting groups include federal and state agencies, professional interest groups, lay community groups, and various mental health and consumer organizations, all of whom have a stake in the nature of the service delivery system (Price and Smith, 1983). What ultimately determines the operative goals of the $\mathrm{CMCHs}$ are the interests of the emerging dominant coalition that controls its key resources. To accommodate to its various constituent members, spheres of organizational activities are designated to respond to specific constituent interests. For example, the development of outpatient services may accommodate the interests of the local psychiatrists, after-care services are aimed to meet the interests of the state department of mental health and the state hospitals, and child mental health services are designed to respond to child advocacy groups. Put differently, the rules for allocating resources in the organization represent the power relations among the various contesting interest groups.

Hence, in response to different constituent groups, CMHCs develop multiple operative goals that often lack integration and coherence. Indeed, these goals may be incompatible with each other as they compete for the same resources. The organization attempts to reduce the ambiguity generated by these goals and preserve its institutional myth, as expressed by the mental health ideology, through the decoupling of various organizational activities and units (Meyer and Rowan, 1977).

Because of these ambiguous goals, the evaluation and inspection system itself becomes detached from actual operations. That is, since the evaluation criteria are diffused and they cannot be readily observed, the evaluation assumes a symbolic pattern, whereby the symbols have only oblique relationship to the organization's actual activities and performances (Hasenfeld, 1983). Thus, most of the voluminous evaluation data generated by $\mathrm{CMHCs}$ shed little light on the quality and effectiveness of services.

\section{IDEOLOGY AND INDETERMINATE TECHNOLOGIES}

CMHCs may be said to be rich in ideology and poor in effective technologies. In fact, it can be argued that ideologies have been used to mask the paucity of productive treatment technologies. From the outset, CMHCs were heralded as new models of mental health treatment based on such ideological principles as primary prevention, social 
rehabilitation, community-based care, comprehensive continuity of care, and utilization of social support networks. A community perspective of mental health assumes that structure and processes at the community level, such as spatial arrangements, economic relations, social stratification, ethnic relations, and the like, have significant impact on the etiology of mental illness and must be modified in order to reduce and prevent pathology. Nevertheless, none of these lofty ideologies and belief systems could be readily, if at all, translated into systematic and operative service technologies.

An operational human service technology can be decomposed into five technological components consisting of specific systems of procedures and action guides (Hasenfend, 1983: 125). These include (1) client-attributes technology, which specifies the characteristics and attributes of the clients to be worked on; (2) knowledge technology, which defines the intervention techniques and knowledge used in the service delivery process; (3) interaction technology, which specifies the interaction patterns used between staff and clients; (4) client-control technology, which defines the client control procedures to be used; and (5) operations technology, which specifies the organization and sequencing of staff activities in the service delivery process.

Psychiatric practice, in general, and community mental health, in particular, are characterized by highly indeterminate technological systems because they are unable to develop rational and coherent systems of procedures and action guides for each technological component that are transferable and generalizable. What characterizes many mental health technological systems is their idiosyncracy, and lack of acceptable level of reliability or validity. Mental health ideologies are, therefore, used to provide the rationale and justification for staff activities as these cannot be derived from a coherent body of knowledge. Rappoport (1960: 269) defines these ideologies as

\footnotetext{
formal systems of ideas that are held with great tenacity and emotional investment, that have self-confirming features, and that are resistant to change from objective rational reappraisal. .. . Ideology welds observable aspects of the environment into a kind of unity by filling in gaps in knowledge with various projections and ultimately supply a coherent belief system on which action can be based and justified.
}

Thus, there are major disparities and discontinuities between the daily work in CMHCs and the ideologies that justify them. These are magnified in CMHCs because of the broad range of mental health problems they attempt to respond to, and in particular because they are required to provide services in a community setting to highly volatile 
clients (i.e., the chronically mentally ill). In contrast to hospital-based psychiatric treatment, their technologies cannot be buffered from the environment, thus making it much more difficult to mask the disparities between action and belief. When coupled with resource constraints, one can readily understand, in this context, the laments of mental health practitioners such as Donovan (1982: 459) who sums up her experience by stating that "community psychiatrists have had many problems and their ranks are diminished... The initial promise of a constructive life in the community for every mentally ill person is the psychiatric equivalent of a promise of a cure for cancer."

Because mental health ideologies cannot provide CMHCs' practitioners with workable technologies, they resort to several strategies in order to reduce uncertainty and formulate manageable work procedures. First, there is a drift toward more established and routine technologies, particularly the use of medication. Second, practitioners lower expectations regarding desired outcomes. Third, they develop, through trial and error and shared experiences, satisfying work procedures for client management that are shaped by the legal, political, and economic contraints they encounter. Fourth, the organization of work is decentralized and segmented so that technological failures in one sphere of services do not adversely affect others.

\section{A LOOSELY COUPLED INTERNAL STRUCTURE}

We have suggested several times throughout this discussion, that centrifugal forces operate on CMHCs that move them to develop a loosely coupled, conglomerate form of organization. We have noted that the heterogeneity and diversity of the clients, the dependency on a turbulent environment with multiple and shifting funding sources, existence of multiple, ambiguous goals, and lack of determinate technologies cast CMHCs into such an organizational mode. What all these factors have in common is that they generate a great deal of uncertainty, unpredictability, and inconsistency, which cannot be accommodated for in a Weberian model of bureaucracy (Litwak, 1978). More important, this analysis indicates that $\mathrm{CMCHs}$ resemble institutionalized organizations. Consequently, in such organizations "formal structures that celebrate institutional myths differ from structures that act efficiently"(Meyer and Rowan, 1977: 355). These formal structures depict a "loosely coupled system" in which work units preserve considerable 
autonomy and identity, and respond to each other in a circumscribed, infrequent, slow, or unimportant manner (Weick, 1976). Such structures have several characteristic features. First, the various tasks and activities that make up the technological core of the organization are weakly coordinated. Second, there is a weak system of control over staff activities as staff exercise considerable discretion in discharging their duties. Third, a weak and often multiple system of authority exists throughout the organization.

A loosely coupled structure permits the organization to manage the inherent disparities and discontinuities between the ideological systems legitimating its existence and the work it performs and outputs it generates. Equally important, it can accommodate multiple and conflicting external and internal interests. In many respects, the internal structure of the CMHC can be said to represent an arena in which interest groups contesting for resources and power arrange themselves in a temporary ordered relationship through control over different organizational activities. CMHCs, for example, have been contested terrain for several helping professions including psychiatry, psychology, social work, psychiatric nursing, and others. When federal and state funds began to pour into CMHCs, they created new opportunities for the helping professions, each clamoring for a share of the pie. Although psychiatry assumed an early dominant position, the mental health ideology and the broad mandate of the CMHCs offered intriguing possibilities to other aspiring professions that hitherto were in a subservient position to psychiatry. Each of these groups has tried to stake a claim for itself by attempting to control one or more of the services and technologies of the organization. Interestingly, as resources have diminished psychiatry seems to be losing some of its interest in CMHCs, as evidenced by the corollary decline in the average number of psychiatrists employed in CMHCs (Bass, 1981).

Nonetheless, a loosely coupled structure that generates redundancies and tolerates inefficiency cannot be readily sustained at times of declining resources. With the increasing pressures on CMHCs to conserve resources and to become cost-efficient, one may see a shift from a loosely coupled system to a more formally structured conglomerate. In such a system, each major service unit in the organization assumes greater operational autonomy while being tightly coupled internally. Moreover, control over resources shifts to headquarters that, in turn, develop elaborate monitoring and control systems. This is exemplified, for instance, through the rapid growth of computerized management information systems in CMHCs. In addition, CMHCs are beginning to 
form subsidiary organizations that specialize in specific segments of the mental health market, both in terms of clients and funding opportunities. These subsidiaries may include for-profit enterprises such as employee assistance programs and nonprofit private agencies that may provide marital counseling or consultation. As a result, the CMHCs come to resemble a holding company with many market-specific subsidiaries.

\section{CONCLUSION}

I would like to suggest that many of the changes and upheavals experienced by $\mathrm{CMCHs}$ can be understood in the context of organizational newness. The CMHCs are a relatively new form of organizations that are still in a process of establishing a firm niche for themselves in an environment that in itself undergoes frequent changes. Many of the organizational characteristics of the CMHCs, are, in part, a consequence of newness. The so-called crisis of community mental health may be temporary growing pains. To quote Hirschman (1982: 43), who addressed the so called crisis of the welfare state, "these pains may well cause considerable trouble when first encountered, but can eventually be brought under control as a result of various learning experiences and mutual adjustments."

I would like to argue that CMHCs are indeed attempting to learn from their experiences and change some of the factors that affect their modes of operation. In their evolutionary development they seem to gradually shift to more familiar and predictable grounds. What are some of the trends that signify such a shift? First, CMHCs are increasingly focusing their attention on the chronically mentally ill as their core clientele, while shifting other clients to independent organizational units. Second, they are moving toward more familiar and proven technologies by giving greater emphasis to treatment via medication coupled with humane custodial services. They have begun to shed untenable technologies and to limit technological innovations to specific client groups within the medical model. Third, by selecting more routine technologies, they are able to establish more bureaucratic work arrangements that emphasize efficiency. In doing so, CMHCs can conserve resources by employing less professional workers. Fourth, they have begun to move away from a loosley coupled structure to a more formalized conglomerate structure in which units and subsidiaries specialize in specific segments of the mixed market economy. 
In this process of "maturing," some organizational components of the CMHCs are gradually coming to resemble more conventional forms of psychiatric care while others begin to resemble commercial enterprises. The big challenge for CMHCs is whether such a conglomerate structure can survive in a rapidly changing and increasingly competitive mental health market.

\section{REFERENCES}

BAKER, F. (1982) "Effects of value systems on service delivery," pp. 246-264 in H. C. Schulberg and M. Killilea (eds.) The Modern Practice of Community Mental Health. San Francisco: Jossey-Bass.

BARDACH, E. (1977) The Implementation Game: What Happens After a Bill Becomes a Law. Cambridge: MIT Press.

BASS, R. (1981) "Trends among core professionals in organized mental health settings: Where have all the psychiatrists gone?" Mental Health Statistical Note 160: 1-11.

CONNERY, R. (1968) The Politics of Mental Health. New York: Columbia Univ. Press.

DINITZ, S. and N. BERAN (1971) "Community mental health as a boundaryless and boundary-busting system." J. of Health and Social Behavior 12: 99-107.

DONOVAN, C. (1982) "Problems of psychiatric practice in community mental health centers." Amer. J. of Psychiatry 139: 456-460.

EMERSON, R. and M. POLLNER (1975) "Dirty work designations: their features and consequences." Social Problems 23: 243-254.

HANNAN, H. T. and J. FREEMAN (1977) "Obstacles to comparative studies," pp. 106-131 in P. S. Goodman and J. Pennings (eds.) New Perspectives on Organizational Effectiveness. San Francisco: Jossey-Bass.

HASENFELD, Y. (1983) Human Service Organizations. Englewood Cliffs, NJ: Prentice-Hall.

HIRSCHMAN, A. O. (1982) Shifting Loyalties. Princeton, NJ: Princeton Univ. Press.

LEVINE, M. (1981) The History and Politics of Community Mental Health. New York: Oxford Univ. Press.

LITWAK, E. (1978) "Organizational constructs and mega bureaucracy," pp. 123-162 in R. C. Sarri and Y. Hasenfeld (eds.) The Management of Human Services. New York: Columbia Univ. Press.

MECHANIC, D. (1980) Mental Health and Social Policy. Englewood Cliffs, NJ: Prentice-Hall.

MEYER, J. and B. ROWAN (1977) "Institutionalized organizations: formal structure as myth and ceremony." Amer. J. of Sociology 83 (September): 340-363.

MEYER, J., W. R. SCOTT, and T. E. DEAL (1981) "Institutional and technical sources of organizational structure: explaining the structure of educational organizations,"pp. 151-179 in H. D. Stein (ed.) Organization and the Human Services. Philadelphia: Temple Univ. Press.

PRICE, R. H. and S. S. SMITH (1983) "Two decades of reform in the mental health system (1963-1983)," pp, 408-437 in E. Seidman (ed.) Handbook of Social Intervention. Beverly Hills, CA: Sage.

RAPPOPORT, R. (1960) Community as a Doctor. London: Tavistock. 
SCHULBERG, H. C. and M. KILLILEA (1982) "Community mental health in transition," pp. 40-94 in H. C. Schulberg and M. Killilea (eds.) The Modern Practice of Community Mental Health. San Francisco: Jossey-Bass.

WAMSLEY, G. L. and M. N. ZALD (1976) The Political Economy of Public Organizations. Bloomington: Indiana Univ. Press.

WARREN, R., S. M. ROSE, and A. F. BERGUNDER (1974) The Structure of Urban Reform. Lexington, MA: D. C. Heath.

WEICK, K. (1976) "Educational organizations as loosely coupled systems." Admin. Sci. Q. 21: 1-19.

WHITE, P. E. (1974) "Resources as determinants of organizational behavior." Admin. Sci.Q. 19: 97-109. 